Diabetologia (1995) 38: 1082-1089

\title{
Increased arterial stiffness in women, but not in men, with IDDM
}

\author{
Å. Rydén Ahlgren ${ }^{1}$, T. Länne ${ }^{2}$, P. Wollmer ${ }^{1}$, B.Sonesson ${ }^{2}$, F.Hansen ${ }^{1}$, G.Sundkvist ${ }^{3}$ \\ ${ }^{1}$ Department of Clinical Physiology, University of Lund, Malmö University Hospital, Malmö, Sweden \\ ${ }^{2}$ Department of Surgery, University of Lund, Malmö General Hospital, Malmö, Sweden \\ ${ }^{3}$ Department of Endocrinology, University of Lund, Malmö General Hospital, Malmö, Sweden
}

\begin{abstract}
Summary For unknown reasons, there is a greater increase in the risk for cardiovascular complications in diabetic women than in diabetic men. Our aim was to study gender-related differences in the mechanical properties of the great arteries in patients with insulin-dependent diabetes mellitus (IDDM) but free from known cardiovascular and cerebrovascular complications. We measured arterial stiffness $(\beta$, inversely related to arterial compliance) in the abdominal aorta and the common carotid artery non-invasively using echo-tracking sonography in 30 women (mean age 34 years, range 20-61) and 26 men (mean age 38 years, range $22-56$ ) with IDDM. The results were compared with those of healthy individuals of corresponding age and gender. The results showed a marked gender-difference in changes of arterial stiffness. Arterial stiffness was increased in both the abdominal aorta and the common carotid artery in dia-
\end{abstract}

betic women compared to control women ( $p=$ 0.0001 and $p=0.0076$, respectively). In contrast, there was no significant difference in stiffness of the abdominal aorta or the common carotid artery between the diabetic men and the control men ( $p=0.69$ and $p=0.39$, respectively). In conclusion, this study has shown that stiffness of the aorta and the common carotid artery is increased in diabetic women but not in diabetic men. Increased arterial stiffness in diabetic women may be a pathogenic factor which could help to explain the gender-related differences in the risk for cardiovascular and cerebrovascular complications in diabetic subjects. [Diabetologia (1995) 38: 1082-1089]

Key words Ultrasonic echo-tracking, insulin-dependent diabetes mellitus, arterial stiffness, gender-difference, arterial compliance.
The high frequency of macrovascular disease among diabetic patients is well-known, and it has been wellestablished that patients with diabetes mellitus have a greater morbidity and mortality from cardiovascular and cerebrovascular disease than do non-diabetic subjects. In addition, diabetes has been shown to be a stronger risk factor for coronary heart disease in women than in men [1-4] and diabetic women have

Received: 7 November 1994 and in revised form: 23 March 1995

Corresponding author: Dr. Å. Rydén Ahlgren, Department of Clinical Physiology, University of Lund, Malmö University Hospital, S-20502 Malmö, Sweden

Abbreviations: IDDM, Insulin-dependent diabetes mellitus; $\beta$, arterial stiffness; MAP, mean arterial blood pressure; AGE, advanced glycation end products. consistently been observed to have a worse prognosis than diabetic men after myocardial infarction, both in studies of the acute course of infarction [5-7] and in long-term epidemiologic studies [2, 3, 7-9]. As for cardiovascular events the risk for cerebrovascular complications is increased more in diabetic women than in diabetic men; the relative risk for stroke is increased in diabetic women compared with diabetic men [10]. In addition, insulin-dependent diabetic women may be particularly vulnerable; death due to myocardial infarction is most common in insulintreated diabetic women $[8,11]$.

The reason for the particularly increased cardiovascular and cerebrovascular morbidity and mortality in diabetic women has not been established. In the search for possible explanations, interest has been focused on early pathologic and pathophysiolo- 
Table 1. Demographic and clinical data in diabetic patients. All data, except frequencies, are presented as mean \pm SD

\begin{tabular}{|c|c|c|}
\hline & $\begin{array}{l}\text { Diabetic } \\
\text { women }\end{array}$ & $\begin{array}{l}\text { Diabetic } \\
\text { men }\end{array}$ \\
\hline Number & 30 & 26 \\
\hline Age (years) & $34 \pm 10.8$ & $38 \pm 9.3$ \\
\hline Duration (years) & $19 \pm 7$ & $19 \pm 8$ \\
\hline Height $(\mathrm{cm})$ & $165 \pm 6$ & $179 \pm 7$ \\
\hline Weight $(\mathrm{kg})$ & $64 \pm 9$ & $76 \pm 7$ \\
\hline Body surface area $\left(\mathrm{m}^{2}\right)$ & $1.7 \pm 0.1$ & $1.9 \pm 0.1$ \\
\hline Body mass index $\left(\mathrm{kg} / \mathrm{m}^{2}\right)$ & $23.4 \pm 2.5$ & $23.7 \pm 2.2$ \\
\hline Albuminuria $>0.5 \mathrm{~g} / 24 \mathrm{~h}$ & 1 & 4 \\
\hline Microalbuminuria $30-300 \mathrm{mg} / 24 \mathrm{~h}$ & 5 & 3 \\
\hline $\begin{array}{l}\text { Retinopathy } \\
\text { Background } \\
\text { More severe than background }\end{array}$ & $\begin{array}{r}11 \\
3\end{array}$ & $\begin{array}{l}8 \\
4\end{array}$ \\
\hline $\mathrm{HbA}_{1 \mathrm{c}}(\%)$ & $8.56 \pm 1.76$ & $7.85 \pm 1.41$ \\
\hline Systolic blood pressure $(\mathrm{mmHg})$ & $121 \pm 11$ & $127 \pm 14$ \\
\hline Diastolic blood pressure (mmHg) & $75 \pm 6$ & $77 \pm 6$ \\
\hline Mean arterial pressure $(\mathrm{mmHg})$ & $91 \pm 7$ & $94 \pm 7$ \\
\hline Pulse pressure (mmHg) & $46 \pm 9$ & $49 \pm 12$ \\
\hline Mean aortic diameter (mm) & $13.5 \pm 1.6$ & $15.6 \pm 1.6$ \\
\hline $\begin{array}{l}\text { Mean common carotid artery } \\
\text { diameter }(\mathrm{mm})\end{array}$ & $7.0 \pm 0.9$ & $7.5 \pm 0.8$ \\
\hline Aortic stiffness (\% predicted) & $164 \pm 56$ & $115 \pm 52$ \\
\hline $\begin{array}{l}\text { Common carotid artery stiffness } \\
\text { (\% predicted) }\end{array}$ & $122 \pm 30$ & $93 \pm 25$ \\
\hline
\end{tabular}

All data, except frequencies presented as mean $\pm \mathrm{SD}$

gic changes in the vasculature. In diabetic patients increased pulse wave velocity [12-14] post-mortem findings [15] and investigations using ultrasound techniques [16] suggest increased arterial stiffness. In these studies, the putative differences between genders have not been analysed. The aim of the present study was therefore to evaluate the mechanical properties of the abdominal aorta and the common carotid artery in patients with insulin-dependent diabetes mellitus (IDDM) and to clarify whether there are gender-related differences in changes of arterial compliance.

\section{Patients and methods}

Thirty women (mean age 34 years, range 20-61) and 26 men (mean age 38 years, range 22-56) with IDDM were investigated. All subjects are followed-up regularly at the Diabetic Clinic at Malmö University Hospital, Sweden, and participate in prospective studies of IDDM $[17,18]$. The mean duration of diabetes was 19 years for both women and men (women: range 9-36 years, men: 9-38 years). None of the patients had a history of acute myocardial infarction or cerebrovascular events or of intermittent claudication. Moreover, none of the patients had angina pectoris or were being treated for coronary artery disease. Clinical details of the patients are given in Table 1; there were no significant differences in clinical features between women and men. One woman and four men showed clinical nephropathy (Table 1); two women were treated for hypertension with furosemide and metoprolol, respectively. Smoking was reported in 12 women and 8 men. All patients gave informed consent according to the Helsinki declaration. To obtain age and gender-matched reference values for abdominal aortic stiffness, a control group of 145 healthy subjects (69 women: age range 4-74 years; 76 men: age range 474 years), was used $[19,20]$. Of these, 43 men and 39 women were in the age range $20-63$ years, i.e. in the age range of the diabetic patients. The reference material for the common carotid artery consisted of 120 healthy subjects (65 women: age range 9-77 years; $55 \mathrm{men}$ : age range $11-77$ years) [21]. Of these 23 men and 31 women were in the age range $20-63$ years, i.e. in the age range of the diabetic patients. None of the control subjects reported previous cardiopulmonary disease, diabetes or smoking and all were free from current medication.

The control subjects were examined by the same staff as the diabetic patients, and the studies of normal subjects and patients were overlapping in time. All measurements were performed with the staff blinded to the clinical data.

Ultrasonic measurements of vascular distensibility. Vessel diameter and pulsatile diameter changes were measured by means of echo-tracking sonography $[22,23]$. We used a recently-developed ultrasound echo-tracking system (Diamove, Teltec AB, Lund, Sweden) capable of detecting vessel wall movements of less than $10 \mu \mathrm{m}[24,25]$. With this equipment pulsatile vessel diameter changes can be measured and in combination with blood pressure measurements, form the basis for calculation of vessel wall stiffness (inversely related to vascular compliance, Kawasaki et al. [26]). This technique has recently been used to evaluate stiffness in the abdominal aorta and the common carotid artery in healthy men and women of different ages [19-21]. Details of the study technique have been described previously [27,28]. The instrument consists of an electronic echo-tracking instrument (Diamove; Lindström et al. [24]) interfaced with a real-time ultrasound scanner (EUB 240; Hitatchi, Tokyo, Japan) and fitted with a 3.5 and $5 \mathrm{MHz}$ linear array transducer [24]. In short, two electronic markers automatically lock to the luminal interface of the echoes from the anterior and posterior vessel wall and follow the pulsatile movements of the vessel wall. The markers are shown in the real-time picture to indicate the level at which the registration is performed. In this system the smallest detectable movement is $8 \mu \mathrm{m} \mathrm{[25]} \mathrm{and} \mathrm{the} \mathrm{time} \mathrm{resolution} \mathrm{is} \mathrm{about} 1.2 \mathrm{~ms}$. A personal computer type 386 (Express, Tokyo, Japan) and a 12-bit analogue to digital converter (Analogue Devices, Norwood, Ma., USA) were used for simultaneous monitoring of the electrocardiogram, arterial blood pressure, and vessel diameter.

All measurements were performed with the subject in the supine position after at least 15 min rest. Differences in indirect blood pressure between the left and right arm were excluded before the investigation. From the real time picture the vessel was insonated in a longitudinal section, the echoes from the vessel walls were optimized and the pulsatile diameter changes were then recorded. Measurements of the right common carotid artery were performed approximately $2-\mathrm{cm}$ proximal to the bifurcation, and the recording of the abdominal aorta was conducted distal to the renal arteries, approximately $3.5-\mathrm{cm}$ proximal to the bifurcation. From each registration a sequence of at least five representative consecutive diameter cycles was manually chosen and the vessel diameters and the diameter changes calculated as means of the selected diameter cycles. Indirect blood pressure measurements were performed immediately after measurements of the pulsatile vessel diameter with a sphygmomanometer and a standard cuff on the left arm. 

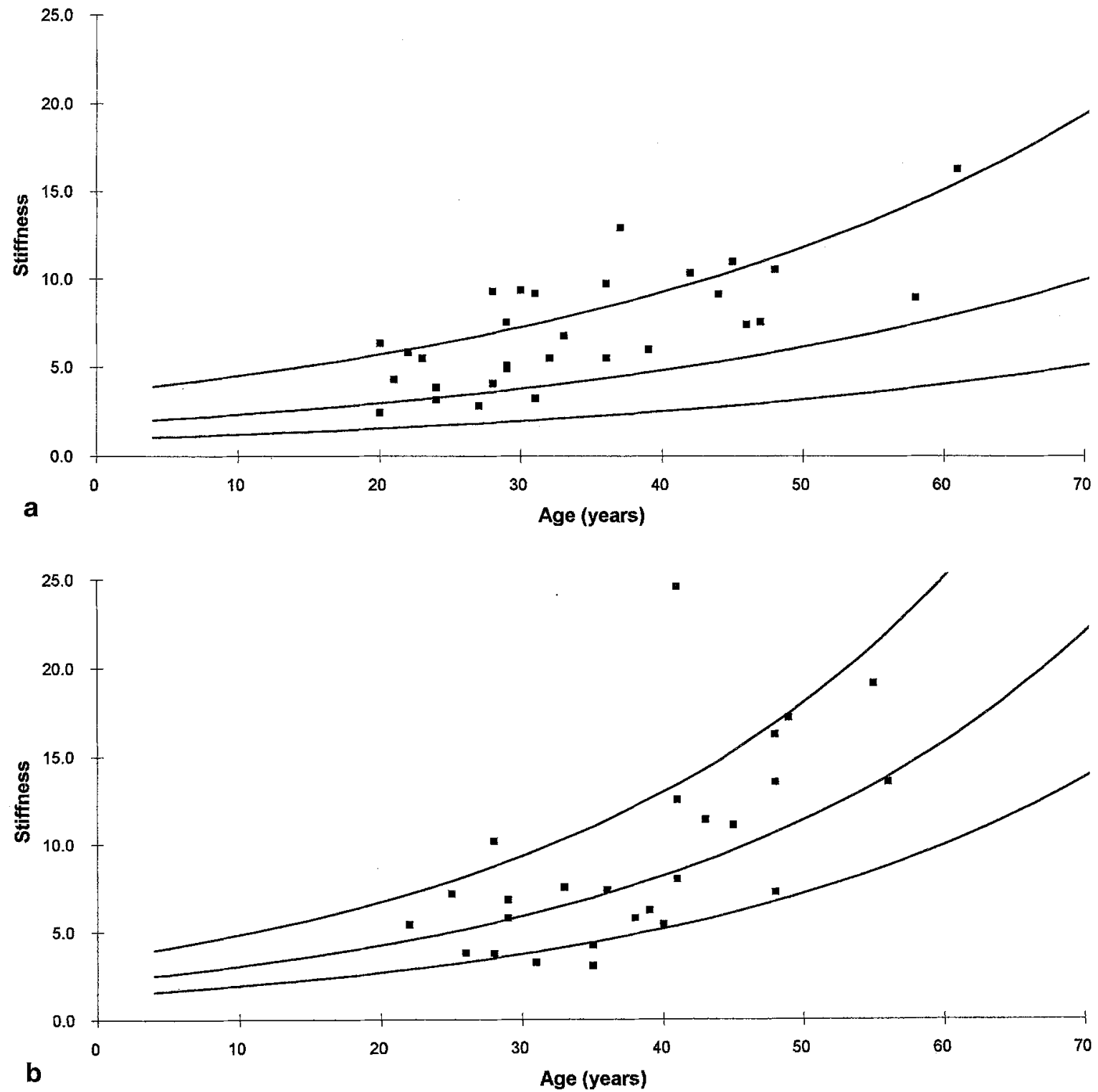

Fig. 1. a Aortic stiffness $(\beta)$ in women with IDDM. Note the increased stiffness $(p=0.0001)$. The solid lines represent mean, upper and lower $95 \%$ confidence interval for the control women. b Aortic stiffness $(\beta)$ in men with IDDM. No increase in stiffness was found $(p=0.69)$. The solid lines represent mean, upper and lower $95 \%$ confidence interval for the control men

The distensibility of the arterial walls was expressed as stiffness $(\beta)$ [26].

$\operatorname{stiffness}(\beta)=\frac{\ln \left(\mathrm{P}_{\text {syst }} / \mathrm{P}_{\text {diast }}\right)}{\left(\mathrm{D}_{\text {syst }}-\mathrm{D}_{\text {diast }}\right) / \mathrm{D}_{\text {diast }}}$

In this equation $P_{\text {syst }}$ and $P_{\text {diast }}$ are the maximal systolic and end-diastolic blood pressure levels $(\mathrm{mmHg}) . \mathrm{D}_{\text {syst }}$ and $\mathrm{D}_{\text {diast }}$ are the corresponding vessel diameters $(\mathrm{mm})$.

Each subject was examined three times at each location with calculation of stiffness from the corresponding diameter, pulsatile diameter change, and blood pressures obtained by the auscultatory method. The average of the values for each subject were calculated. Mean arterial blood pressure (MAP) was taken as the diastolic pressure plus one third of the pulse pressure. Using this technique the variabilities for repeated measurements of the pulsatile diameter change are 10-15\% and for stiffness $15-20 \%$ for the vessels investigated [28]. As both age and gender influence diameter and stiffness [20,21], women and men were studied separately. Since the aortic diameter is also related to body surface area [29] the aortic diameters were corrected for the body surface area according to $\mathrm{Du}$ Bois and Berlington [30].

Duplex scanning of the carotid artery. To evaluate the possible presence of atherosclerotic plaques, a duplex ultrasound examination of the carotid vessels was performed using an Acuson $128 \mathrm{XP} / 10$ colour doppler (Mountain View, $\mathrm{Ca}$, USA) with a $7.5 \mathrm{MHz}$ linear array transducer for the real-time B-mode imaging and a $4.5 \mathrm{MHz}$ pulsed doppler. The axial resolution of this system was $0.3 \mathrm{~mm}$. If plaques were found, the maximum peak velocity in the internal carotid artery was used to assess the severity of the stenosis. 


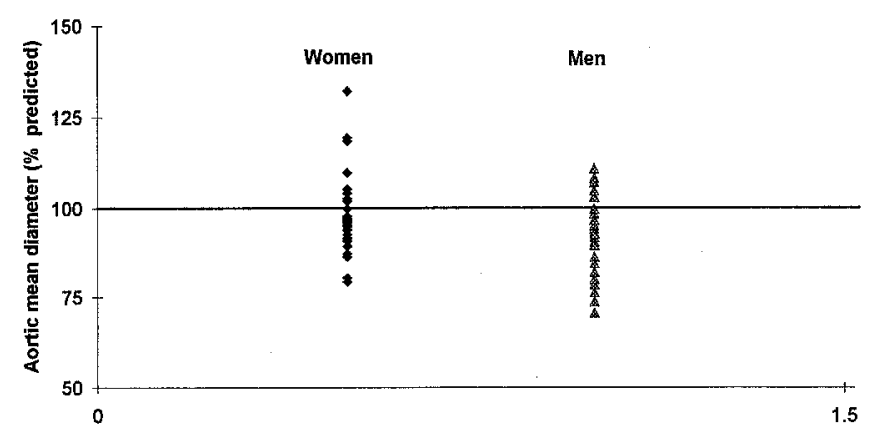

Fig. 2. Aortic mean diameter in men and women with IDDM expressed as per cent predicted value according to age and gender (no correction for body surface area). The diameter was decreased in both diabetic men and women $(p=0.0007$ and $p=0.0021$, respectively).

\section{Statistical analysis}

Analyses of non-linear regression with $95 \%$ confidence intervals for individual and mean prediction were used to define the normal ranges for stiffness and MAP in the control subjects according to age and gender. Analysis of covariance was then used to compare stiffness, MAP and the mean vessel diameters in diabetic women and men with control subjects in corresponding age ranges as stated in patients and methods. Analysis of residuals was employed to test that the assumptions for the models were satisfied. The results were also expressed as a percentage of individually predicted values. Differences in arterial stiffness between smoking and non-smoking patients (using the percent of predicted values) and differences in clinical characteristics $\left(\mathrm{HbA}_{1 \mathrm{c}}\right.$, blood pressure) were statistically tested with a non-parametric test (Mann-Whitney U-test). $p<0.05$ was taken as significant. Data are presented as the mean value $\pm \mathrm{SD}$, unless otherwise stated.

\section{Results}

Mean arterial blood pressures in the diabetic patients (Table 1) did not differ significantly from those in the control group of corresponding age, either for women (91 \pm 7 vs $91 \pm 8$ ) or for men ( $94 \pm 7$ vs $91 \pm 10$ ).

Stiffness of the aorta. Diabetic women showed significantly higher aortic stiffness (Fig.1 a) than control women $(p=0.0001)$, whereas diabetic men did not show any significant difference in aortic stiffness (Fig. 1b) compared with control men $(p=0.69)$. The distal abdominal aortic diameter was significantly decreased in both diabetic men and diabetic women compared with the corresponding control subjects whether corrected for body surface area or not (women $p=0.0001$ and $p=0.0021$, respectively, and men $p=0.0013$ and $p=0.0007$, respectively), although the differences between diabetic and control subjects were small (Fig.2, Table 1). When the diabetic women were compared with the diabetic men (age-corrected) no significant difference in stiffness was observed $(p=0.64)$.
Stiffness of the common carotid artery. In agreement with the findings in the abdominal aorta, diabetic women showed significantly increased stiffness in the common carotid artery compared with the control women $(p=0.0076)$, whereas diabetic men did not show any significant difference in stiffness $(p=0.39)$ compared with control men (Fig. 3a, 3b). In contrast to the findings in the abdominal aorta, however, no significant differences in the common carotid artery's internal diameter were noted for either diabetic women or diabetic men, compared with the control subjects.

Duplex scanning of the carotid arteries. Almost all patients had a normal appearance of the carotid arteries. One man (48 years old, 20 years' duration of diabetes) had a $45 \%$ stenosis in the left internal carotid artery close to the bifurcation and one woman (44 years old, 20 years duration) showed a soft plaque resulting in a $45 \%$ stenosis of the right internal carotid artery close to the bifurcation. In addition, three of the oldest women ( $>44$ years old) and three of the oldest men showed discrete, small plaques with normal flow velocities.

Arterial stiffness and clinical features. No obvious significant correlations between aortic stiffness and the duration of diabetes or the presence of retinopathy were detected. The $\mathrm{HbA}_{1 \mathrm{c}}$ levels in diabetic women did not differ significantly from those of diabetic men (Table 1). There were no significant differences in aortic or common carotid artery stiffness between the smoking and the non-smoking patients for either women or men (Fig. 4a, 4b).

The women with nephropathy, who also had proliferative retinopathy, showed a high aortic stiffness ( $257 \%$ predicted). The aortic stiffness values in the three women with proliferative retinopathy were 257, 248 and $167 \%$ predicted (mean $224 \%$ predicted) and showed a tendency to be higher than in diabetic women without proliferative retinopathy (mean $157 \%$ predicted). The aortic stiffness values in the five women with microalbuminuria were 96 , $167,206,248$ and $213 \%$ predicted (mean $186 \%$ predicted). The aortic stiffness values in the four men with nephropathy were $97,151,156$ and $159 \%$ predicted (mean $141 \%$ predicted). The aortic stiffness values for the four men with proliferative retinopathy were $129,96,130$ and $156 \%$ predicted (mean $128 \%$ predicted). The aortic stiffness values in the three men with microalbuminuria did not differ from those without microalbuminuria $(80,117$ and $100 \%$ predicted, mean $100 \%$ predicted). No correlations between the common carotid stiffness and duration, retinopathy, nephropathy or microalbuminuria could be detected. 

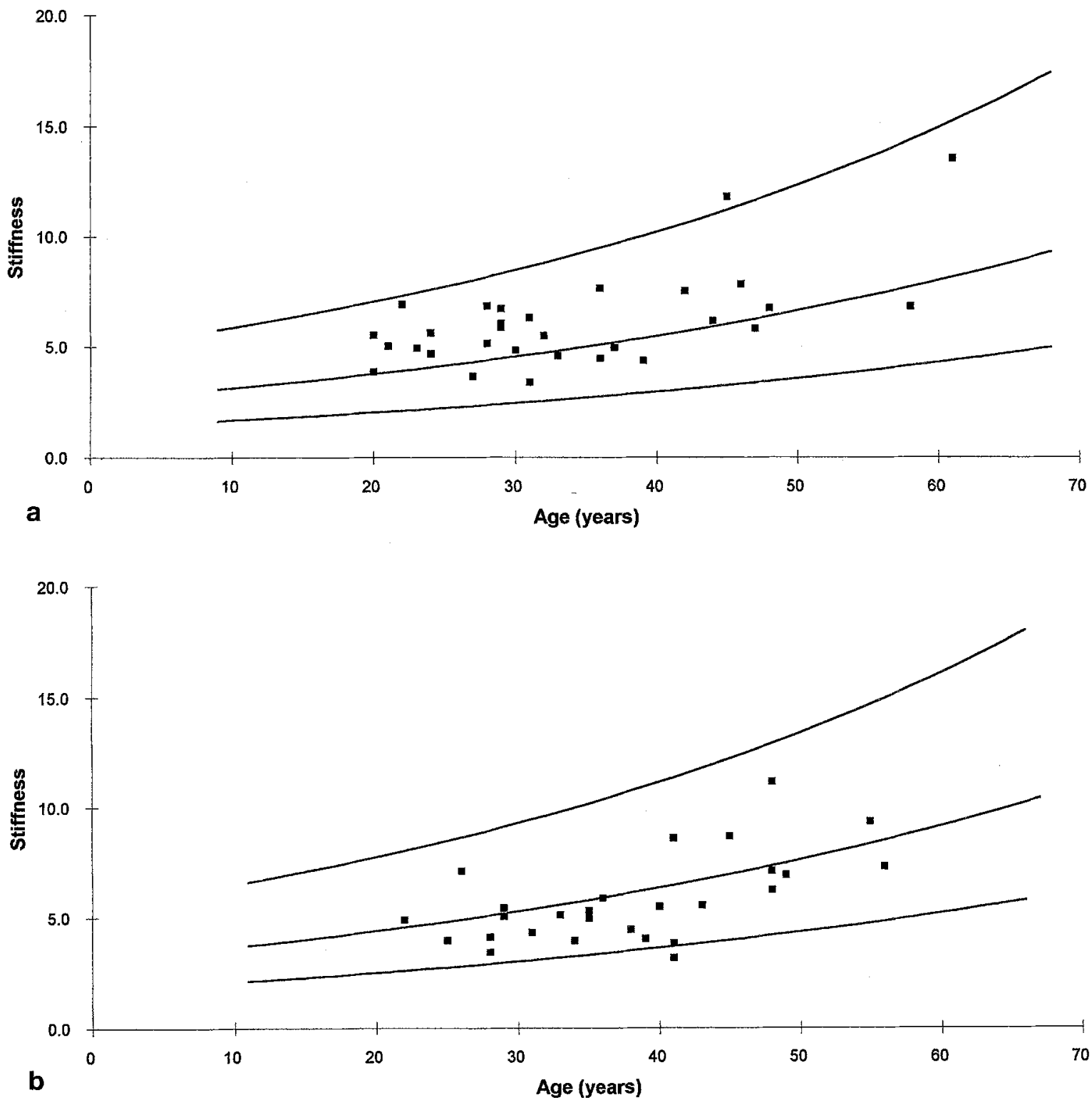

Fig. 3. a Common carotid artery stiffness $(\beta)$ in women with IDDM. Note the increased stiffness $(p=0.0076)$. The solid lines represent mean, upper and lower $95 \%$ confidence interval for the control women. b Common carotid artery stiffness $(\beta)$ in men with IDDM. No increase in stiffness was found $(p=0.39)$. The solid lines represent mean, upper and lower $95 \%$ confidence interval for the control men

\section{Discussion}

This study has shown the stiffness of the aorta and the common carotid artery to be increased in diabetic women but not in diabetic men. The difference between genders found in non-diabetic, middle-aged subjects $[20-21]$ was thereby absent in patients with IDDM.

Calculation of the mechanical properties of arteries are based on the pressure/diameter relationship which is non-linear with a more distensible wall at smaller than at larger distensions [31] and any measurement of arterial distensibility must be considered in relation to the blood pressure. In this study MAP did not differ between the diabetic women and the control women nor between the diabetic men and the control men. Moreover, when distensibility is expressed as stiffness $(\beta)$, the dependence on pressure in the physiological range is largely abolished $[19,26,27]$. In our calculation of stiffness $(\beta)$, indirectly measured blood pressure in the brachial artery is assumed to be equal to the blood pressure in the abdominal aorta and common carotid artery. It is, however, well-known that the arterial pressure-waves undergo transformation in the arterial tree, and therefore, the pulse pressure in the brachial artery is higher than in more central vessels. Comparison between intra-arterial pressure in the aorta and brachial pressure obtained by the auscultatory method has shown that pulse pressure is slightly 


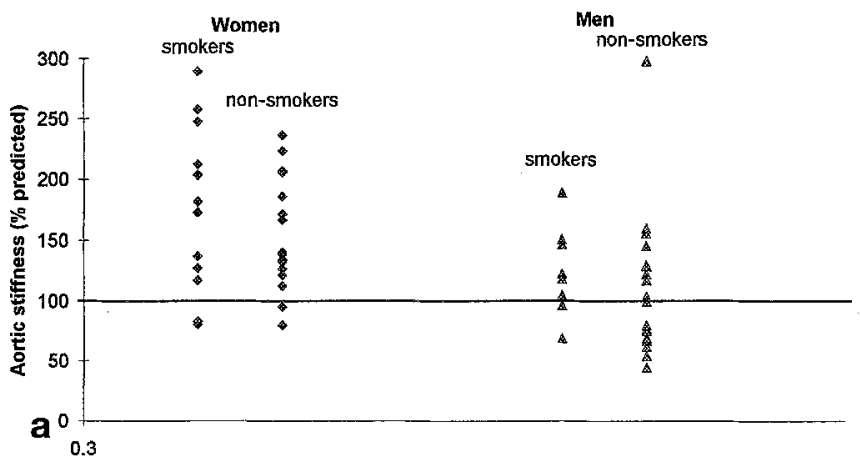

non-diabetic subjects is smoking, since some of the diabetic patients investigated were smokers, whereas all control subjects were non-smokers. However, there was no significant difference in stiffness between smoking and non-smoking patients (Fig. $4 \mathrm{a}, 4 \mathrm{~b}$ ), and the difference in arterial stiffness between diabetic women and control subjects remains statistically significant if non-smokers alone are analysed. Thus, our findings cannot be explained by differences in smoking habits.

The duration of disease as well as the frequency of

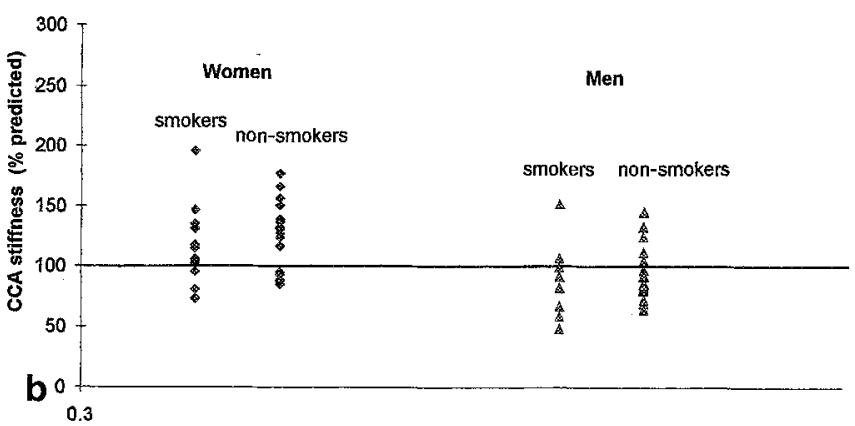
complications was similar in diabetic men and women, indicating that the gender difference in arterial stiffness is not explained by the stage of the disease process.

Atherosclerosis may be another factor involved in the stiffening of the arterial walls. The great majority of the patients investigated had normal appearance of their carotids and were without visible plaques at the site of measurements in the abdominal aorta. A recent study has reported intima-media thickenings in the carotid artery in young patients with diabetes [41]. The finding was interpreted to represent atherosclerotic lesions. Data concerning gender differences are, however, lacking.

Several previous in vitro and non-invasive in vivo studies with other techniques have shown decreased arterial distensibility in large vessels in diabetic patients [12-16]. In these previous studies, the potential difference between genders in changes of arterial compliance was not analysed and some of these previous studies did not take the normal age and gender variations of compliance into account. One of these studies also included both insulin-dependent and non-insulin-dependent diabetic patients [14].

In contrast, Lehmann et al. [42], using pulse wave velocity, found increased aortic compliance (more distensible aortas) in IDDM patients compared to age- and gender-corrected control subjects. This may seem contradictory to our observations. The patients with IDDM investigated by Lehmann et al., however, were young $(<13$ years) with short diabetes duration ( $<1$ year), whereas our patients were older (range 20-61 years) with long duration of IDDM (range 9-38 years). Accordingly, there may be a gradual decrease in arterial compliance with increasing diabetes duration although this could not be shown in our study, probably due to the fairly long diabetes duration in all our patients.

We have no obvious explanation for our finding of a gender-related difference in changes of arterial stiffness in diabetic patients. There is, however, epidemiologic evidence supporting differences in the development of vascular disease between men and women with diabetes. Diabetes is a stronger risk factor for coronary heart disease in women than in men [1-4] and women have been shown to have a worse prognosis after myocardial infarction than that of dia- 
1088

betic men $[2-3,5-9,11]$ with reports of a higher incidence of congestive heart failure, re-infarction and death. Moreover, diabetes seems to be a stronger risk factor for stroke in women than in men [10].

The function of the aorta is an important determinant of the performance of the left ventricle. It has been speculated that reduction of left ventricular and arterial compliance may contribute to the abnormal susceptibility of diabetic patients to congestive heart failure, particularly during the acute stages of myocardial infarction [7]. Our finding of increased arterial stiffness in diabetic women may therefore contribute to the understanding of the particularly poor prognosis in diabetic women after myocardial infarction.

Non-enzymatic glycation of proteins occurs in diabetes and advanced glycation end products (AGEproducts) can accumulate in long-lived proteins such as vascular collagen and form cross-links with other matrix proteins and plasma proteins [43]. Recent studies, using pulse wave velocity, have shown a correlation between AGE-products and vascular compliance $[14,44]$. Although no apparent correlation between $\mathrm{HbA}_{1 \mathrm{c}}$ and arterial stiffness was found in our study, excessive accumulation of AGE-products on matrix proteins in vessel walls may contribute to increased stiffness of the arteries in diabetes. To the best of our knowledge, no data about gender differences in accumulation of AGE-products are available. An increase in hyaluronic acid in the tunica media of the aorta, as recently reported in patients with IDDM [45], as well as accumulation of fibronectin [46] and type IV collagen [47] could also be relevant to our findings.

In conclusion, this study has shown the stiffness of the aorta and the common carotid artery to be increased in women with IDDM but not in men with IDDM. Thus, long-standing diabetes seems to abolish the normal sex difference in aortic distensibility between men and women. These findings may contribute to explaining the frequent congestive heart failure and preclinical echocardiographic abnormalities of left ventricular function in diabetic women.

Acknowledgements. This study was supported by the Swedish Heart Lung Foundation, the Swedish Diabetes Association, the Novo-Nordic Foundation, The Lundström Foundation and the Swedish Medical Research Council (No.00660 and No.7507).

\section{References}

1. Kannel WB, McGee DL (1979) Diabetes and cardiovascular disease: the Framingham study. JAMA 241: 2035-2038

2. Heyden S, Heiss G, Bartel AG, Hames CJ (1980) Sex-differences in coronary mortality among diabetics in Evans County, Georgia. J Chronic Dis 33: 265-273

3. Barret-Conner E, Wingard DL (1983) Sex differential in ischemic heart disease mortality in diabetics: a prospective population-based study. Am J Epidemiol 118: 489-496
A. Rydén Ahlgren et al.: Arterial stiffness in diabetic patients

4. Lerner DJ, Kannel WB (1986) Patterns of coronary heart disease morbidity and mortality in the sexes: a 24-year follow-up of the Framingham population. Am Heart J 111: 383-390

5. Soler NG, Benett MA, Pentecost BL, Fitzgerald MG, Malins JM (1975) Myocardial infarction in diabetics. Q J Med 44: 125-132

6. Tofler GH, Stone PH, Muller JE et al. (1987) Effects of gender and race on prognosis after myocardial infarction: adverse prognosis for women, particularly black women. J Am Coll Cardiol 9: 473-482

7. Stone PH, Muller JE, Hartwell T (1989) The effect of diabetes on prognosis and serial left ventricular function after acute myocardial infarction: contribution of both coronary artery disease and diastolic left ventricular dysfunction to the adverse prognosis. J Am Coll Cardiol 14: 49-57

8. Garcia MJ, McNamara PM, Gordon T, Kannel WB (1974) Morbidity and mortality in diabetics in Framingham population: sixteen year follow-up study. Diabetes 23: $105-111$

9. Kannel W (1985) Lipids, diabetes, and coronary heart disease: insights from the Framingham study. Am Heart J 110: 1110-1117

10. Bell D (1994) Stroke in the diabetic patient. Diabetes Care 17: 213-219

11. Czyzk A, Krolewski AS, Szablowska S, Alot A, Kopczynski J (1980) Clinical course of myocardial infarction among diabetic patients. Diabetes Care 3: 526-529

12. Woolam GL, Schnur PL, Valbona C, Hoff HE (1962) The pulse wave velocity as an early indicator of atherosclerosis in diabetic subjects. Circulation 25: 533-539

13. Pillsbury HC, Hung W, Kyle MC, Freis ED (1974) Arterial pulse waves and systolic time intervals in diabetic children. Am Heart J 87: 783-790

14. Airaksinen KEJ, Salmela PI, Linnaluoto MK, Ikäheimo MJ, Ahola K, Ryänen L (1993) Diminished arterial elasticity in diabetes: association with fluorescent advanced glycosylation end products in collagen. Cardiovasc Res 27: 942-945

15. Oxlund H, Rasmussen LM, Andreassen TT, Heickendorff L (1989) Increased aortic stiffness in patients with type 1 (insulin-dependent) diabetes mellitus. Diabetologia 32: $748-758$

16. Christensen B, Neubauer T (1987) Arterial wall stiffness in insulin-dependent diabetes mellitus. Acta Radiol 28: 207209

17. Bergström B, Lilja B, Österlin S, Sundkvist G (1987) Autonomic neuropathy in type 1 diabetes: influence of duration and other diabetic complications. Acta Med Scand 22: $147-154$

18. Sundkvist G, Velloso LA, Kämpe O et al. (1994) Glutamic acid decarboxylase antibodies, autonomic nerve antibodies and autonomic neuropathy in diabetic patients. Diabetologia 37: 293-299

19. Länne T, Sonesson B, Bergqvist D, Bengtsson H, Gustafsson D (1992) Diameter and compliance in the male human abdominal aorta: influence of age and aortic aneurysm. Eur J Vasc Surg 6: 178-184

20. Sonesson B, Hansen F, Stale H, Länne T (1993) Compliance and diameter in the human abdominal aorta - the influence of age and sex. Eur J Vasc Surg 7: 690-697

21. Hansen F, Mangell P, Sonesson B, Länne T (1995) Diameter and compliance in the human common carotid artery variations with age and sex. Ultrasound Med Biol 21: 1-9

22. Arndt JO, Klauske J, Mersch F (1968) The diameter of the intact carotid artery in man and its change with pulse pressure. Pflugers Arch 301: 230-240 
23. Hokansson DE, Mozersky DJ, Sumner DJ, Strandness DE Ir (1972) A phase-locked echo-tracking system for recording arterial diameter changes in vivo. J Appl Physiol 32: $728-733$

24. Lindström K, Gennser G, Sindberg Eriksson P, Bentin M, Dahl P (1987) An improved echo-tracker for studies on pulse-waves in the fetal aorta. In: Rolfe $P$ (ed) Fetal physiological measurements. Butterworths, London, pp 217-226

25. Benthin M, Dahl P, Ruzicka R, Lindström K (1991) Calculation of pulse wave velocity using cross correlations effects of reflexes in the arterial tree. Ultrasound Med Biol 17: 461-469

26. Kawasaki T, Sasayama S, Yagi S-I, Asakawa T, Hirai T (1987) Non-invasive assessment of the age related changes in stiffness of major branches of the human arteries. Cardiovasc Res 21: 678-687

27. Länne T, Stale H, Bengtsson H et al. (1992) Noninvasive measurement of diameter changes in the distal abdominal aorta in man. Ultrasound Med Biol 18: 451-457

28. Hansen F, Bergqvist D; Mangell P, Rydén $\AA$, Sonesson B, Länne T (1993) Non-invasive measurement of pulsatile vessel diameter changes and elastic properties in human arteries: a methodological study. Clin Physiol 13: 631-643

29. Sonesson B, Länne T, Hansen F, Sandgren T (1994) Infrarenal aortic diameter in the healthy person. Eur J Vasc Surg 8: 89-95

30. Du Bois BS, Berlington WT (1916) Clinical calorimetry. 10 th paper. A formula to estimate the approximate surface area if height and weight be known. Arch Int Med 17: 863

31. Dobrin P (1983) Vascular mechanics. In: Shephard JT, Abbound FM (eds) Handbook of physiology, Part 1. Peripheral circulation and organ blood flow, Vol.3. Williams and Wilkins, Baltimore, pp 65-102

32. Imura T, Yamamoto K, Kanamori K, Mikami T, Yasuda H (1986) Non-invasive ultrasonic measurement of the elastic properties of the human abdominal aorta. Cardiovasc Res 20: 208-214

33. Sonesson B, Vernersson E, Hansen F, Länne T (1994) Sex differences in the mechanical properties of the abdominal aorta in man. J Vasc Surg 20: 959-969

34. Ho K-J, Lin C-Y, Galysh FT, Patel AS, Liu LB, Taylor CB (1972) Aortic compliance. Studies on its relationship to aortic constituents in man. Arch Pathol 94: 537-546

35. Burton AC (1954) Relationship of structure to function of the tissues of the wall of blood vessels. Physiol Rev 34: $619-642$
36. Roach MR, Burton AC (1957) The reason for the shape of the distensibility curves of arteries. Can J Biochem Physiol 35: $681-690$

37. Wolinsky H, Glaskov S (1964) Structural basis for the static mechanical properties of the aortic media. Circ Res 14: 400-413

38. Powell JT, Adamson J, MacSweeney STR, Greenhalg RM, Humpries SE, Henney A (1991) Genetic variants of collagen III and abdominal aortic aneurysm. Eur J Vasc Surg 5: $145-148$

39. Sonesson B, Hansen F, Länne T (1994) Abnormal mechanical properties of the aorta in Marfan's syndrome. Eur J Vasc Surg 8: 595-601

40. Christensen T, Jörgensen J, Neubauer B (1988) Increased arterial wall stiffness and thickness in medium-sized arteries in patients with insulin-dependent diabetes mellitus. Acta Radiol 29: 299-302

41. Yamasaki Y, Kawamori R, Matsushima H et al. (1994) Atherosclerosis in carotid artery of young IDDM patients monitored by ultrasound high-resolution $B$-mode imaging. Diabetes 43: 634-639

42. Lehmann ED, Gosling RG, Sönksen PH (1992) Arterial wall compliance in diabetes. Diabet Med 9: 114-119

43. Brownlee M, Cerami A, Vlassara H (1988) Advanced glycosylation end products in tissue and the biochemical basis of diabetic complications. N Engl J Med 318: 1315-1321

44. Monnier VM, Vishwanath V, Frank KE, Elmets GA, Dauchot P, Kohn RR (1986) Relation between complications of type 1 diabetes mellitus and collagen-linked fluorescence. N Engl J Med 314: 403-408

45. Heickendorff L, Ledet T, Rasmussen LM (1994) Glycosaminoglycans in the human aorta in diabetes mellitus: a study of tunica media from areas with and without atherosclerotic plaque. Diabetologia 37: 286-292

46. Rasmussen LM, Heickendorff L (1989) Accumulation of fibronectin in aortas in diabetic patients. A quantitative immunohistochemical and biomedical study. Lab Invest 61 : $440-446$

47. Rasmussen LM, Ledet T (1993) Aortic collagen alterations in human diabetes mellitus. Changes in basement membrane collagen content and in the susceptibility of total collagen to cyanogen bromide solubilisation. Diabetologia 36 : $445-453$ 